\title{
Sustentabilidade e turismo: renda, preservação e entretenimento em uma área de preservação
}

\section{Sustainability and tourism: income, preservation and entertainment in a preservation area}

Sostenibilidad y turismo: renta, conservación y entretenimiento en un área de preservación

Vanessa Alberton ${ }^{1}$ Luis Paulo Gomes Mascarenhas ${ }^{2}$ Ronaldo Ferreira Maganhotto ${ }^{3}$ Cláudio Shigueki Suzuki ${ }^{4}$

${ }^{1}$ Mestre em Desenvolvimento Comunitário e bacharel em Turismo pela Universidade Estadual do Centro-Oeste (UNICENTRO), campus Irati, PR. Desenvolve pesquisas nas áreas de turismo em áreas naturais, ecoturismo e turismo de aventura. E-mail: valbertontur@gmail.com, ORCID: http://orcid.org/0000-0002-8045-4832

${ }^{2}$ Doutor em Saúde da Criança e do Adolescente. Mestre em Atividade Física e Saúde. Bacharel em Educação Física. Docente no curso de Licenciatura em Educação Física e no Programa de Pós-Graduação Interdisciplinar em Desenvolvimento Comunitário na Universidade Estadual do Centro-Oeste (UNICENTRO). E-mail: Imascarenhas@unicentro.br, ORCID: http://orcid.org/0000-0002-7762-2727

${ }^{3}$ Doutor e mestre em Geografia. Bacharel em Turismo. Docente no Departamento de Turismo e no Programa de Pós-Graduação Interdisciplinar em Desenvolvimento Comunitário, na Universidade Estadual do Centro-Oeste (UNICENTRO). E-mail: ronaldomaganhotto@gmail.com, ORCID: http://orcid.org/0000-0003-0659-1481

${ }^{4}$ Doutor e mestre em Ciências. Bacharel em Educação Física. Docente no Departamento de Educação Física e no Programa de Pós-Graduação Interdisciplinar em Desenvolvimento Comunitário, na Universidade Estadual do Centro-Oeste (UNICENTRO).E-mail: suzuki@unicentro.br, ORCID: http://orcid.org/0000-0002-3756-1245 
Vanessa ALBERTON; Luis Paulo Gomes MASCARENHAS;

Ronaldo Ferreira MAGANHOTTO; Cláudio Shigueki SUZUKI

Resumo: Tem o objetivo de descrever o processo de implantação da Reserva Particular do Patrimônio Natural "Ninho do Corvo" e verificar se esse empreendimento é compatível com a conservação da natureza, geração de renda, de modo a ser considerado um empreendimento sustentável. Utilizou-se de pesquisa qualitativa, por meio de um estudo de caso, observação direta, pesquisa bibliográfica e de campo, com aplicação de entrevista semiestruturada. Entre os principais resultados, destaca-se que o empreendimento emprega moradores locais, auxilia em pequenas proporções para o desenvolvimento do município, destaca-se como área de preservação aliando atividades de turismo e preservação ambiental. Conclui-se que seria interessante o empreendimento investir em programas de educação ambiental para envolver a comunidade local e desenvolver parcerias com mais empreendimentos vizinhos, a fim de estimular ainda mais a economia local.

Palavras-chave: unidades de conservação; Desenvolvimento Local; preservação; turismo.

\begin{abstract}
It has the objective to describe the process of implantation of the Private Reserve of the Natural Heritage "Corvo Nest" and verify if this venture is compatible with a conservation of nature, income generation, and can be considered a sustainable enterprise. Qualitative and quantitative research was used, through a case study, direct observation, bibliographical and field research, with semi-structured interview application. The results obtained were: the project employs local residents, helps in small proportions for the development of the municipality, and stands out as a preservation area combining activities of tourism and environmental preservation. It was concluded that it would be interesting to the venture investing in environmental education programs to involve the local community and developing partnerships with more ventures neighbors, to further stimulate the local economy.
\end{abstract}

Keywords: conservation units; Local Development; preservation; tourism.

Resumen: Tiene como objetivo describir el proceso de implementación de la reserva privada de Patrimonio Natural "Nido del Cuervo" y verificar si esta empresa es compatible con la conservación de la naturaleza, generación de ingresos, con el fin de ser considerada una empresa sostenible. Utiliza la investigación cualitativa, a través de un estudio de caso, observación directa, investigación bibliográfica y de campo, con aplicación de entrevista semiestructurada. Se obtuvieron los siguientes resultados: el proyecto emplea a residentes locales, ayuda en pequeñas proporciones para el desarrollo de la ciudad, se destaca como un área de preservación combinando turismo y actividades de preservación del medio ambiente. Se llegó a la conclusión de que sería interesante para la empresa invertir en programas de educación ambiental para involucrar a la comunidad local y las sociedades en desarrollo con más vecinos de empresas, con el fin de estimular la economía local.

Palabras clave: unidades de conservación; Desarrollo del Sitio; preservación; turismo. 


\section{INTRODUÇÃO}

A atividade turística, importante geradora de renda do setor terciário da economia, representa uma maneira significativa de se trabalhar a educação ambiental. Por meio do turismo em áreas naturais, é possível desenvolver diversas atividades em segmentos como o turismo de aventura e o ecoturismo, ambos priorizando a preservação da natureza e a sustentabilidade, englobando seus três pilares de sustentação: ambiental, econômico e social.

Aliar a preservação da natureza, a inserção da comunidade, a sustentabilidade e a geração de renda se apresenta como uma dificuldade recorrente, sendo o empecilho de sucesso de empreendimentos de pequeno e médio porte, que não conseguem conciliar o desenvolvimento desses elementos de forma conjunta. Entretanto, por meio da oferta de produtos e serviços turísticos, é possível tornar o empreendimento diferenciado e aumentar as chances reais de ser bem-sucedido.

Quando se trata de turismo em áreas protegidas, surge o conflito: preservação e uso. As áreas protegidas, do mundo todo, recebem números cada vez maiores de turistas, porém muitas não estão preparadas para receber a atividade de maneira tão intensa. Por isso, faz-se fundamental a educação ambiental e o cumprimento de normas e regras, seguindo o estabelecido pelas diretrizes específicas.

No município de Prudentópolis, localizado a cerca de $200 \mathrm{~km}$ de Curitiba, capital do Paraná, criou-se uma Reserva Particular do Patrimônio Natural (RPPN), onde são desenvolvidas atividades ligadas ao ecoturismo e turismo de aventura.

\section{REFERENCIAL TEÓRICO}

\subsection{As áreas de preservação}

No ano de 2000, com a aprovação da Lei 9.985, que institui o Sistema Nacional de Unidades de Conservação da Natureza (SNUC), diversas áreas naturais passaram a ser consideradas como Unidades de Conservação, cujo principal objetivo é "contribuir para a manutenção da diversidade biológica 
e dos recursos genéticos no território nacional e nas águas jurisdicionais" (BRASIL, 2000, Art. 4으, inciso I, s. p.).

Entre as categorias que compõem esse sistema, destaca-se a Reserva Particular do Patrimônio Natural (RPPN), que faz parte das Unidades de Conservação de Uso Sustentável e tem como objetivo principal proteger os recursos ambientais significativos para a região em que está inserida. Nessas reservas, podem ser desenvolvidas atividades de cunho científico, cultural, educacional, recreativo e de lazer, entre as quais se destaca o turismo em áreas naturais, definido pela Secretaria de Estado do Turismo do Paraná (PARANÁ, 2000, p. 4) como sendo um utilizador do

[....] patrimônio natural e cultural, de forma sustentável, com intercâmbio sob diferentes formas entre o homem e a natureza, para promover a conservação dos recursos locais (físicos e humanos), otimizando os custos e ganhos ambientais, culturais, econômicos e sociais, orientado por planejamentos participativos.

No estado do Paraná, são 259 RPPNs reconhecidas, sendo 229 instituídas no âmbito estadual (via Instituto Ambiental do Paraná [IAP]), 15 federais (via Instituto Chico Mendes de Conservação da Biodiversidade [ICMBio]) e 15 municipais (via prefeituras). O montante dessas 244 unidades é de mais de 54 mil hectares de áreas preservadas, distribuídas em 98 municípios (IAP, 2017).

Entre essas áreas, citamos algumas RPPNs que trabalham com a atividade turística: RPPN do Sebuí (Guaraqueçaba); RPPN Itáytyba (Tibagi); RPPN Ninho do Corvo (Prudentópolis); RPPN Reserva Natural Salto Morato (Guaraqueçaba); RPPN Reserva Natural Serra do Itaqui (Guaraqueçaba); RPPN Reserva Papagaios Velhos (Palmeira); e RPPN Sítio Serra do Tigre (Ivaí).

Para melhor compreensão de como se dá o processo de utilização turística no interior das áreas protegidas, será abordado, a seguir, sobre o ecoturismo e como o setor pode ser visto como uma forma de renda e desenvolvimento local.

\subsection{Atividades de turismo em áreas naturais protegidas}

Praticar o turismo em áreas naturais é uma das principais motivações de viagens. O meio ambiente é considerado por Ruschmann (1997) como 
a matéria-prima do turismo e ambos têm uma relação incontestável. Na década de 1980, o termo ecoturismo começou a ser usado por CeballosLascuráin (apud FENNEL, 2002, p. 42), definindo o ato de viajar para áreas naturais "relativamente não perturbadas nem contaminadas com o objetivo específico de estudar e admirar o cenário, seus animais e plantas selvagens, assim como quaisquer manifestações culturais (passadas e presentes) encontradas nessas áreas".

O ecoturismo é importante para um país como o Brasil, na medida em que traz benefícios, como: diversificar a economia regional por meio do surgimento de micro e pequenas empresas; gerar empregos locais; influenciar a população rural a permanecer no campo; melhorar as infraestruturas de transporte, comunicação e saneamento; criar alternativas de arrecadação para as Unidades de Conservação; diminuir o impacto sobre o patrimônio natural, cultural e o plano estético-paisagístico; e melhorar os equipamentos nas áreas protegidas (AGÊNCIA BRASILEIRA DE PROMOÇÃO INTERNACIONAL DO TURISMO [EMBRATUR], 1994).

Pires (2002) compara o ecoturismo com outro segmento em alta na atualidade: o turismo de aventura. Neste, prefere-se a movimentação física e as situações desafiadoras que o meio natural pode oferecer. O Ministério do Turismo define esse segmento como sendo os "movimentos turísticos decorrentes da prática de atividades de aventura de caráter recreativo e não competitivo", em que as "experiências físicas e sensoriais recreativas que envolvem desafios e que podem proporcionar sensações diversas como liberdade, prazer e superação" variam conforme a expectativa, o envolvimento, a vivência do turista e o nível de dificuldade de cada atividade realizada (BRASIL, 2010, p. 14-15).

Um diferencial do segmento de turismo de aventura que tem apresentado benefícios para os prestadores de serviços é o fato de que eles podem aliar suas paixões pelas atividades com seus afazeres profissionais, transformando em uma nova profissão o que antes eram apenas momentos de lazer e aventura. 


\subsection{O turismo como estratégia de fomento ao desenvolvimento comunitário}

Muito se fala sobre os benefícios e as consequências da atividade turística em todo o mundo. É fato que, em algumas comunidades, há um desconforto da comunidade receptora, como aponta estudo feito por James Jordan, em 1980, ao analisar a implantação do turismo em uma vila norte-americana, em New Jersey. O autor relata que, na visão dos moradores, "[...] o turismo aparece como um fardo que a comunidade deve suportar" e, mesmo reconhecendo-o como importante fonte de renda, representa "[...] a perda da tranquilidade e da privacidade da população local" (JORDAN, 1980 apud BANDUCCI JR; BARRETO, 2001, p. 29).

Por outro lado, o turismo tem uma força enquanto fenômeno sociocultural, abrangendo fatores comportamentais da comunidade receptora e dos visitantes, além das "[...] inter-relações do turismo com as diversas tradições e culturas das regiões visitadas" (GOMES, 2007, s. p).

Dessa forma, a atividade turística causa consequências, tanto negativas como positivas, na comunidade local. Destacamos aqui os benefícios relacionados à "[...] valorização do artesanato local, da herança cultural, orgulho étnico, valorização e preservação do patrimônio histórico-cultural, intercâmbio cultural, troca de valores, vivência emocional e espacial, melhoria em infra-estrutura pública" (GOMES, 2007, s. p.), geração de empregos e renda.

A atividade turística está ligada ao meio ambiente, e a comunidade é detentora de uma grande responsabilidade em relação às questões de envolvem esse campo. Além disso, o desenvolvimento sustentável tem como uma de suas pedras fundamentais "[...] a ideia de que a comunidade local deve participar ativamente no planejamento do turismo, e talvez controlar a indústria do turismo local e suas atividades" (SWARBROOKE, 2000, p. 59).

Para que haja o desenvolvimento de uma comunidade, é necessário o sincronismo de diversos elementos, que vão além das questões financeiras para determinar as melhorias na qualidade de vida. Portanto, é preciso considerar também o desenvolvimento social, histórico-cultural, ambiental, entre outros. Cada uma dessas vertentes tem elementos constituintes e, dentro do desenvolvimento sustentável, é preciso trabalhar a sustentabi- 
lidade ambiental, requisito básico de manutenção dos espaços utilizados pela atividade turística.

Para se alcançar a sustentabilidade ambiental, Sachs (2004, p. 15-16) definiu cinco pilares que devem ser lapidados, sendo de interesse desta pesquisa apenas três: social, ambiental e econômico, conceituados a seguir.

a - Social, fundamental tanto por motivos intrínsecos quanto instrumentais, por causa da perspectiva de disrupção social que paira de forma ameaçadora sobre muitos lugares problemáticos do nosso planeta;

b-Ambiental, com as suas duas dimensões (os sistemas de sustentação da vida como provedores de recursos e como "recipientes" para a disposição de resíduos);

$[\ldots]$

d - Econômico, sendo a viabilidade econômica a conditio sine qua non para que as coisas aconteçam.

Para que haja progresso em todos esses itens, muita coisa tem de ser feita até, enfim, chegar-se ao tão esperado desenvolvimento sustentável. As comunidades rurais podem incrementar a renda oferecendo serviços turísticos, como: hospedagem, alimentação, trilhas, venda de produtos artesanais locais, além de oferecer ao visitante a possibilidade de vivenciar diferentes ambientes rurais (NOVAES apud REJOWSKI; COSTA, 2003). É necessário pensar em ações que fomentem o desenvolvimento como um todo, em todas as suas dimensões, pois, dessa forma, acredita-se que haverá maiores chances de a comunidade obter sucesso em experiências de crescimento, inclusive investindo em atividades do setor turístico.

O turismo em áreas naturais, de acordo com Eagles (2001 apud VIANA; NASCIMENTO, 2009), é um mercado em plena expansão e que depende de dois componentes fundamentais: níveis de qualidade ambiental e níveis de satisfação do cliente. Entende-se que tais componentes devem ser considerados igualmente na organização de um empreendimento. Entretanto, observa-se, em muitos casos, que na medida em que a satisfação do cliente é colocada em primeiro plano, na busca da geração de renda, a qualidade ambiental é deixada de lado, tornando-se um problema social a ser reparado. 
O desenvolvimento de atividades turísticas no meio natural, quando mal planejado, causa consequências negativas para a comunidade local e para o meio ambiente. Por outro lado, quando bem executado, promove diversos benefícios para a comunidade, tais como a construção de novas vias de comunicação e de acesso, maior valorização das áreas naturais e criação de novos postos de trabalho para atender às demandas dos visitantes (DIAS, 2003).

\section{MATERIAIS E MÉTODOS}

Trata-se de uma pesquisa com abordagem qualitativa, que teve como objetivo descrever o processo de implantação do empreendimento turístico Ninho do Corvo e verificar se esse empreendimento desenvolve ações de conservação da natureza e geração de renda, bem como se vem a ser um empreendimento sustentável. A pesquisa qualitativa é caracterizada por Minayo (2010, p. 21-22) como aquela que "[...] trabalha com o universo de significados, motivos, aspirações, crenças, valores e atitudes, o que corresponde a um espaço mais profundo das relações, dos processos e dos fenômenos", que não podem ser medidos em números.

Optou-se por adotar como procedimento o estudo de caso, que, de acordo com Gil (2002, p. 54), “Consiste no estudo profundo e exaustivo de um ou poucos objetos, de maneira que permita seu amplo e detalhado conhecimento". O estudo de caso tem diferentes propósitos, tais como: "[...] explorar situações da vida real cujos limites não estão claramente definidos"; e "[...] descrever a situação do contexto em que está sendo feita determinada investigação" (GIL, 2002, p. 54).

Para melhor entender os significados e elementos não quantificáveis, optou-se por realizar entrevista, que permite adquirir um conhecimento subjetivo, expresso de forma única e espontânea. A entrevista semiestruturada seguiu o método survey, recomendado para situações em que se pretende responder a questionamentos do tipo: o quê, por quê, como e quanto. Com o tipo descritivo, com corte-transversal, coletaram-se dados em um único momento, sem necessidade de analisar variáveis ao longo do tempo (FREITAS et al., 2000). 
A pesquisa foi desenvolvida na RPPN Ninho do Corvo, no município de Prudentópolis, entre os meses de julho de 2015 e maio de 2016, e foram entrevistados: o proprietário da RPPN; oito funcionários (fixos e temporários); dois empreendimentos turísticos do entorno; dez turistas presentes nos momentos de pesquisa; um representante do poder público; e dois estudantes do curso de Bacharel em Turismo que realizavam estágio no local.

Para González Rey (2002, p. 97), no processo de coleta de dados, "[...] o curso da produção de informação é, simultaneamente, um processo de produção de ideias em que toda nova informação adquire sentido para a pesquisa". Portanto, conforme as informações foram surgindo nas entrevistas e a pesquisadora foi agrupando-as, soube-se se havia a necessidade de novas entrevistas ou não.

Foi realizada uma pesquisa bibliográfica, buscando o embasamento teórico necessário para proporcionar melhor abordagem dos conteúdos que se relacionam com o objeto de estudo. Entre esses conteúdos, destacam-se temas como: RPPN; o Ninho do Corvo; ecoturismo; sustentabilidade; e atividades de aventura.

A pesquisa documental permitiu conhecer o histórico da propriedade, o planejamento interno e as ações voltadas para as atividades de aventura. Tais informações foram obtidas do Plano de Manejo, que consiste em um documento técnico que segue as orientações do Roteiro Estadual para Elaboração de Planos de Manejo, proposto pelo IAP em agosto de 2009, e "[...] apresenta o histórico da RPPN Ninho do Corvo, o diagnóstico contemplando os meios abióticos, bióticos e antrópicos e o planejamento proposto para a RPPN, com o zoneamento e os programas de manejo" (RPPN NINHO DO CORVO, 2009, p. 13).

\section{RESULTADOS E DISCUSSÃO}

\subsection{O município de Prudentópolis}

O município de Prudentópolis está localizado na região sudeste paranaense, cerca de $200 \mathrm{~km}$ de Curitiba. De acordo com o Instituto Brasileiro de Geografia e Estatística (IBGE, 2010), somava uma população de 48.792 habitantes, sendo que, desse total, quase $54 \%$ residia no meio rural (cerca 
de 26.329 pessoas). A área territorial é de $2.236,579 \mathrm{~km}^{2}$, resultando em uma densidade demográfica de 21,14 habitantes por km².

O território pertence ao bioma Mata Atlântica, tem clima temperado subtropical, com verões frescos e fortes geadas durante o inverno. Por estar posicionado na transição entre o Segundo e o Terceiro Planalto Paranaense, o relevo apresenta altitudes que variam de 480 metros a 1.170 metros de altitude.

O fato de o relevo apresentar declives acentuados influenciou na formação dos rios da região, acarretando vales profundos e canyons originados pelos processos exógenos de modelação de tal relevo, o que teve relação direta com as dezenas de cachoeiras gigantes localizadas no município e, consequentemente, tornou o município propício para a prática de atividades de aventura.

O município tem no turismo uma fonte de renda, com dezenas de atrativos naturais, culturais e religiosos, cujo início das atividades se deu por volta de 1990, quando "[...] publicações de abrangência nacional levaram o município a ser chamado de 'Terra das Cachoeiras Gigantes'. Com a chegada de turistas, aparecem os primeiros condutores de turismo, em grupos organizados" (PRUDENTÓPOLIS, 2015, p. 14). A partir de então, surgiram empreendimentos ligados ao setor, como hotéis, pousadas e agência de turismo.

Aos poucos, o município foi desenvolvendo políticas específicas para o setor, e a comunidade interessada se organizou para buscar alternativas, por meio da criação Conselho Municipal de Turismo e das ações realizadas pela Secretaria Municipal de Turismo.

\subsection{A RPPN Ninho do Corvo}

Localizada na Linha Paraná, a 25 km do centro do município de Prudentópolis, a propriedade conhecida como uma Reserva Particular do Patrimônio Natural foi adquirida em 2002, e, no dia 5 de dezembro de 2007, a RPPN foi legalizada e reconhecida em nível estadual pelo Instituto Ambiental do Paraná, com 10,59 hectares de mata preservada (RPPN NINHO DO CORVO, 2009). 
A RPPN pertence ao Modelo $\mathrm{C}$ de Unidades de Conservação, em que o "[...] grau de restrição de uso dos recursos é inversamente proporcional aos impactos negativos causados, ou seja, quanto menos restritivo for o uso aumenta a probabilidade de que os impactos decorrentes de seu uso serão inevitáveis" (IAP, 2009, p. 21). Nele, é permitido desenvolver atividades de proteção ambiental, pesquisa científica com "[...] fins conservacionistas, educação, treinamento, capacitação, restauração e recuperação ambiental" (IAP, 2009, p. 21) e atividades de recreação e turismo sustentável.

Na figura 1, é possível observar o zoneamento desenvolvido na elaboração do Plano de Manejo, identificando o uso da propriedade, sendo: (A) onde há as estruturas físicas e recepção; (B) zona de visitação; e (C) zona de proteção.

Figura 1 - Área delimitando a RPPN

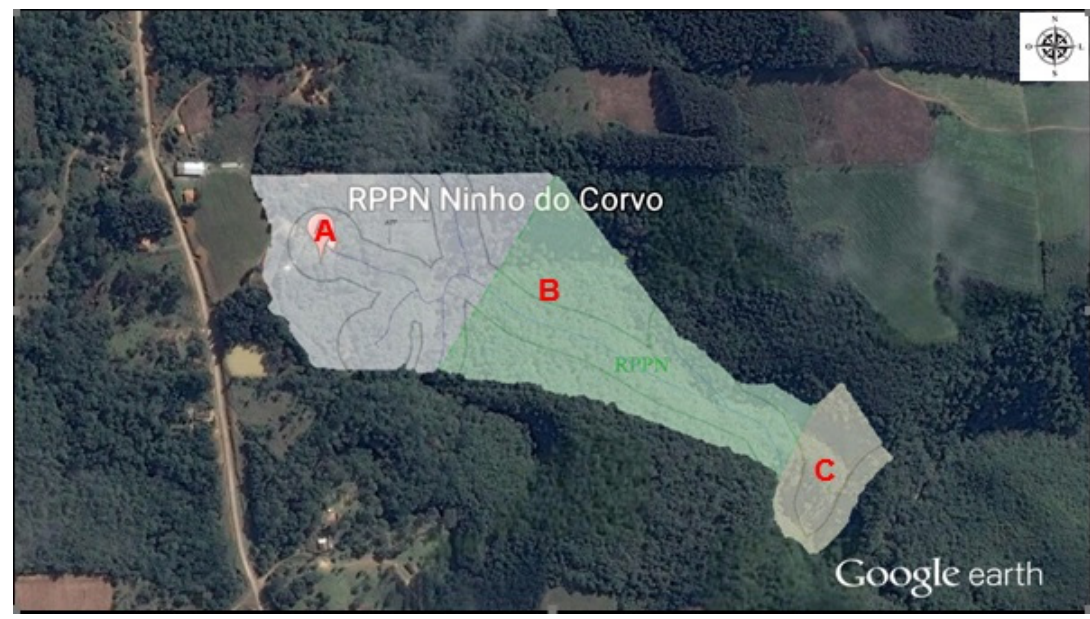

A - Estruturas físicas, tirolesa etc.

Coordenadas UTM

B - Zona de visitação

Longitude -51.1127419

$\mathrm{C}$ - Zona de proteção Latitude - 25.064659o

Fonte: Google Earth. Adaptado.

A área pertence ao bioma Mata Atlântica e com o ecossistema caracterizado como floresta ombrófila mista com formação montana, encontrada atualmente em poucas reservas particulares e no Parque do Iguaçu, na região Sul, e a qual ocupava quase que inteiramente o planalto acima dos 500 m de altitude (LOPES, 2015). Tem o clima subtropical úmido, com chu- 
vas frequentes e temperaturas superiores a 25 ㄷ C no verão, com geadas no inverno. A flora é variada, destacando a Araucária angustifolia, popularmente conhecida como pinheiro-do-paraná (RPPN NINHO DO CORVO, 2009).

A fauna é composta por dezenas de espécies, como: anfíbios, aves, mamíferos terrestres (quati, esquilo, paca), voadores (morcegos) e lepidópteros (borboletas). Essa variedade de espécies aumenta a importância de preservar o meio ambiente, e as áreas de proteção particulares são vistas como opções cada vez mais comuns para alcançar este fim.

O terreno tem declividades acentuadas e, antes da aquisição, era utilizado na produção agrícola, com o uso de queimadas para limpar o solo, degradando-o e alterando suas características naturais (RPPN NINHO DO CORVO, 2009). Tal prática causa "[...] danos ao solo, como a eliminação de nutrientes essenciais às plantas. As queimadas também trazem uma série de prejuízos à biodiversidade, a dinâmica dos ecossistemas e a qualidade do ar" (EMBRAPA, 2015, s. p.).

A RPPN está localizada no segundo Planalto paranaense, subunidade Planalto de Prudentópolis, que, de acordo com a caracterização do Serviço Geológico do Paraná (MINEROPAR), tem topos aplainados, vertentes convexas e vales em forma de $V$ aberto. Nessa subunidade, a altitude varia entre 580 metros e 1.040 metros do nível do mar, com uma área total de 2.628 $\mathrm{km}^{2}$ (MINEROPAR, 2006).

A propriedade é banhada pelo Rio Barra Bonita, pertencendo à Bacia do Rio Ivaí. Além de duas nascentes na área preservada, tem atrativos naturais de valor significativo, como as cachoeiras Ninho do Corvo, Cachoeira do Funil, Salto Boqueirão, Cachoeira Água Verde (RPPN NINHO DO CORVO, 2009).

\subsection{A atividade turística na RPPN Ninho do Corvo}

O empreendimento oferece ao visitante trilhas, cachoeiras, canyons e atividades de recreação, como a tirolesa, rapelesa (misto de rapel com tirolesa guiada) e corvolesa (tirolesa controlada por um condutor capacitado, em que o turista desce em um cabo de aço sob o canyon).

Em parceria com a Cooperativa Paranaense de Turismo, desenvolve treinamentos vivenciais com grupos de funcionários de empresas, que é 
uma forma de contornar a variação de sazonalidade, visto que o fluxo de turistas é maior nos períodos quentes do ano.

O empreendimento tem duas opções de hospedagem, ambas no estilo rústico, com detalhes modernos e acomodando até 10 pessoas. No quadro a seguir, é possível visualizar uma síntese das atividades desenvolvidas.

Quadro 1 - Síntese das atividades desenvolvidas na RPPN

\begin{tabular}{|c|l|}
\hline ATIVIDADE & \multicolumn{1}{|c|}{ DESCRIÇÃo } \\
\hline Tirolesa & $\begin{array}{l}\text { Cem metros de descida aérea, suspensão por dois cabos } \\
\text { de aço }\end{array}$ \\
\hline Corvolesa & $\begin{array}{l}\text { Tirolesa com } 140 \text { metros, guiada pelo condutor, passando } \\
\text { pelo canyon Barra Bonita }\end{array}$ \\
\hline Rapelesa & $\begin{array}{l}\text { Rapel guiado (com cordas) de } 70 \text { metros, passando pelo } \\
\text { canyon Barra Bonita }\end{array}$ \\
\hline Trilhas & $\begin{array}{l}\text { Cerca de } 2 \text { km de caminhos definidos em meio à mata, } \\
\text { levando a cachoeiras, mirante e paisagens de beleza } \\
\text { natural }\end{array}$ \\
\hline Eventos corporativos e & $\begin{array}{l}\text { Atividades de um dia (para grupos), com o intuito de } \\
\text { integrar a equipe por meio de uma gincana }\end{array}$ \\
\hline treinamentos vivenciais & $\begin{array}{l}\text { Percorrendo estradas rurais até mirantes, cachoeiras e } \\
\text { igrejas }\end{array}$ \\
\hline Expedições & Viagens para o Sul do Brasil e países da América do Sul \\
\hline
\end{tabular}

Fonte: Plano de Manejo. Autoria própria.

Quando se fala em turismo, com destaque para o turismo de aventura, que é praticado dentro da RPPN Ninho do Corvo, há uma aceitação por parte dos funcionários entrevistados, que veem a atividade como algo positivo. O turismo é visto como algo bom para a Reserva, pois, se não o houvesse, a área pesquisada não teria sido adquirida e, consequentemente, transformada.

De modo geral, as atividades de turismo desenvolvidas dentro da área de preservação contribuem de alguma forma para o desenvolvimento local, relacionando-se com os três pilares da sustentabilidade, conforme segue nos tópicos adiante, trazendo os questionamentos aplicados aos entrevistados. 


\subsubsection{Contribuições sociais}

O empreendimento estudado, por meio da oferta de atividades de turismo, proporciona contribuições sociais para os envolvidos. Na época da pesquisa, foram abordados oito funcionários, sendo quatro fixos (identificados como A, B, C, D) e quatro freelancers (identificados como E, F, G, H). Destes, 50\% residem a uma distância de $2 \mathrm{~km}$ da RPPN, o que apresenta facilidade nos deslocamentos e evidencia geração de empregos para a comunidade local.

Periodicamente, são realizados cursos de capacitação para os funcionários, de modo que a maioria dos entrevistados já teve a oportunidade de participar. São cursos relacionados com os afazeres rotineiros e preventivos, tais como boas práticas de manipulação de alimentos e competências mínimas de condutores e de primeiros socorros. Os que não participaram receberam as orientações e os conhecimentos no dia a dia, por meio da convivência com os colegas capacitados.

Até o momento da pesquisa, não havia relatos de cursos sobre sensibilização e educação ambiental. É um tipo de educação voltada ao meio ambiente, tentando fazer com que as pessoas se sensibilizem, interessem-se por ele e pelos problemas correlatos, utilizando de seus "[...] conhecimentos, aptidões, atitudes, motivações e desejos necessários para trabalhar individual e coletivamente na busca de soluções aos problemas atuais e para prevenir os que podem aparecer na sequência" (UNESCO, 1975, p. 3) (tradução nossa).

Um total de cinco dos oito funcionários entrevistados estava, na época da pesquisa, conseguindo proporcionar melhores condições financeiras para a família. Alguns destacaram que o fato de estar em contato com a natureza amenizou situações de estresse e de problemas psicológicos. Além disso, alguns funcionários tiveram alterações significativas no modo de vida, tal como deixar de ser agricultor e de usar agrotóxicos, apresentando melhorias no cotidiano e na saúde. Ter contato com pessoas e culturas diferentes, obter novos aprendizados, melhorar os relacionamentos familiares, oportunidade de conhecer novas pessoas e ter sentimentos de alegrias e satisfação são relatos considerados pertinentes, uma vez que refletem o bem-estar dos funcionários em permanecer no ambiente de trabalho. 
A atividade turística está relacionada com a "[...] possibilidade de inclusão social; desenvolvimento de ações para minimizar seus impactos negativos e maximizar os positivos [...]; análise e previsão de tendências de desenvolvimento do turismo" (PANOSSO NETO, 2010 apud SCÓTOLO; PANOSSO NETO, 2015, p. 39). Partindo desta ideia de inclusão social, nota-se que o empreendimento turístico é um elemento gerador de empregos e, consequentemente, de renda. Para ampliar os resultados, o trabalho conjunto com poder público e o trade turístico também são ações que podem gerar desenvolvimento e benefícios para os envolvidos.

Nas proximidades da RPPN Ninho do Corvo, estão localizados dois empreendimentos ligados à atividade turística. Ambos têm trilhas, cachoeiras, hospedagem, oferecem alimentação e áreas de descanso. Foram entrevistados os dois proprietários com o intuito de averiguar a sinergia e o compartilhamento de demanda entre os dois. Tanto o empreendimento A como o B têm uma demanda oriunda de municípios como Curitiba, Londrina, Maringá, São Paulo e um número menor de visitantes da região de Prudentópolis. Em ambas, ocorre uma parceria com a RPPN, pois vários turistas que se deslocam para fazer as atividades na Reserva acabam fazendo as refeições, acampando ou visitando as redondezas.

A proprietária do empreendimento A afirma que a demanda da RPPN ajuda a desenvolver a comunidade, ainda que de forma pequena. Ela relata que apenas alguns turistas mencionam que o deslocamento até Prudentópolis se deve, principalmente, ao fato de conhecer a RPPN; acredita-se que isso se deve justamente por serem públicos distintos que frequentam os dois empreendimentos.

Questionado sobre a relevância de ter uma área de preservação nas proximidades, o proprietário do empreendimento B menciona que isso é importante, pois é necessário "[...] preservar, ter os animais, a natureza, as belezas naturais", e ele acredita que a demanda recebida na área de preservação ajuda a desenvolver a comunidade local, já que os turistas compram produtos artesanais das associações locais.

Para complementar algumas informações, foram abordados dez turistas, sendo seis homens e quatro mulheres, com idades variando entre 23 e 55 anos. Vale destacar que cinco deles estavam na RPPN em função 
de um treinamento vivencial oferecido pela cooperativa em que trabalham. Seus municípios de origem são Colombo (1), Curitiba (2), Marechal Cândido Rondon (5) e Maringá (2). Destaca-se que nenhum dos turistas entrevistados conhecia a RPPN Ninho do Corvo e apenas um já havia estado em Prudentópolis anteriormente.

A motivação em se deslocar até o empreendimento turístico Ninho do Corvo envolve intenções variadas, tais como: estar próximo à natureza; fugir da correria da cidade; ter todas as atividades desejadas em um mesmo local; busca por esportes radicais; e por ser um roteiro de cooperativas (treinamento vivencial).

Os turistas foram questionados sobre quantos dias permaneceriam na RPPN e no município. Entre os dez entrevistados, nove passaram uma noite hospedados no município, sendo seis em hotéis no centro da cidade, dois na RPPN e um no empreendimento A. Apenas três entrevistados conseguiram visitar alguns atrativos turísticos do entorno, porém todos têm interesse em retornar para Prudentópolis e conhecer novos atrativos e recursos turísticos, pois, na viagem em que foram entrevistados, não haveria tempo hábil para novas visitas.

Seguindo o pensamento de Panosso Neto (p. 17, apud SCÓTOLO; PANOSSO NETO, 2015, p. 39), em que o turismo está relacionado com “[...] coleta de dados qualitativos e quantitativos; produção de conhecimentos críticos na busca de sua melhor compreensão", buscamos identificar, em dois estagiários que auxiliaram nos treinamentos vivenciais, elementos que contribuíssem para a complementação da importância da existência da RPPN Ninho do Corvo. Trata-se de dois alunos do curso de Bacharelado em Turismo, na UNICENTRO, campus Irati. Quando questionados sobre o que é uma RPPN, ambos se posicionaram como conhecedores do assunto, destacando a importância de ter espaços preservados, tanto para o meio ambiente como para a população.

Destaca-se a opinião do estagiário A: "Acho que as pessoas deveriam cultivar e cuidar mais", pois são inúmeros os benefícios que a natureza proporciona. O meio acadêmico instiga a sensibilização ambiental, e a oportunidade de ligar a teoria à prática faz com que seja fixado o conhecimento adquirido e se tenha a chance de praticar o aprendido. 
Em relação ao poder público, foi entrevistada uma funcionária da Secretaria de Turismo de Prudentópolis, com o intuito de verificar se são desenvolvidas ações voltadas ao turismo no município e se a comunidade é envolvida nestes processos. Obtiveram-se respostas positivas para os dois questionamentos, destacando ações como: reestruturação do Centro de Informações Turísticas (CIT); promoção da I e II Caminhada Internacional na Natureza e 1ㅇ Passeio Ciclístico Rural; reuniões de reaproximação com empresários locais ligados ao turismo e com entidades públicas; participação em eventos, levando informações do município, gastronomia e exposição de artesanato local; levantamento de placas de sinalização novas e antigas; realização de curso gratuito de "Agente de Informações Turísticas", em parceria com o SENAC; manutenção de mirante, principais acessos turísticos, praças, portal da cidade; retomada do Conselho Municipal de Turismo; e implantação do curso de graduação em Turismo, pela UNICENTRO.

Há o planejamento para desenvolver diversas outras ações nos próximos anos, portanto, na medida do possível, o setor público contribui com o básico para as condições de desenvolvimento turístico do empreendimento estudado, enfatizando que não é permitida a intervenção da prefeitura nas áreas pertencentes a propriedades particulares.

Em relação ao envolvimento da comunidade no desenvolvimento do turismo, reconhece-se que a cada dia a comunidade se envolve mais com as questões relacionadas ao turismo. De acordo com a entrevistada representante do poder público, "Depois que a Secretaria realizou a I Caminhada Internacional na Natureza, as pessoas perceberam o valor e as riquezas" que o município possui "e que realizando eventos, atraindo turistas gera um certo lucro, além da troca cultural e os laços de amizade que permanecem" ${ }^{1}$.

\subsubsection{Contribuições ambientais}

Na época da elaboração do plano de manejo, meados de 2008, realizou-se um seminário participativo com a comunidade do entorno imediato, "[...] aproximando-os dos objetivos de conservação da natureza e

${ }^{1}$ Entrevista concedida a Vanessa Alberton, pela funcionária da Secretaria de Turismo de Prudentópolis, representando o poder público, em Irati, 18 de maio de 2016. 
possibilitando a troca de informações e experiências, fundamentais para as ações de planejamento" (RPPN NINHO DO CORVO, 2009, p. 13). Constatouse que a maioria dos moradores entrevistados sabia da existência da área protegida, porém desconhecia o termo RPPN. Partindo dessas informações, em outubro do mesmo ano, foi realizado um seminário com "[...] objetivo principal de sensibilizar os moradores quanto à importância da conservação do meio ambiente" (RPPN NINHO DO CORVO, 2009, p. 15).

$\mathrm{Na}$ ocasião, houve uma aproximação entre a RPPN e a comunidade, "[...] possibilitando trocas de conhecimentos e experiências entre a equipe organizadora, o proprietário e a comunidade" (RPPN NINHO DO CORVO, 2009, p. 15). Essa relação deve ser estimulada para que permaneça acesa no dia a dia, possibilitando a ajuda mútua e a conservação dos recursos naturais da comunidade.

Atualmente, a RPPN não tem um programa de educação ambiental, porém seria interessante desenvolvê-lo integrando o turista, o funcionário e a comunidade. Sugere-se que o empreendimento receba alunos do ensino fundamental e médio, apresentando a eles o que é uma área de preservação, qual a importância de cuidar do meio ambiente e os benefícios que ele traz para toda a comunidade.

Para o estagiário $A$, as pessoas que trabalham na RPPN têm uma consciência ambiental diferenciada, pois conhecem a realidade interna e aprendem a cuidar da natureza de uma forma única e intensa. Embora seja mínima, a mobilização que o empreendimento proporciona faz a diferença para quem está envolvido, disseminando os cuidados ambientais em seu círculo de convivência.

Em relação à área de preservação, destaca-se o fato de algumas espécies animais voltarem a viver na região devido à presença de mata nativa, funcionando como um corredor ecológico, abrigando uma diversidade de espécies também da flora. Além do mais, é a única área reconhecida como RPPN no município, sendo considerada um ponto positivo para a comunidade.

O empreendimento turístico RPPN Ninho do Corvo, comprovadamente por meio de seu histórico, preserva a natureza em sua forma mais pura, por meio da restauração da mata nativa antes devastada pelas queimadas. Por 
meio dessa ação, espécies da flora e da fauna voltaram a habitar a região, além do registro de nascentes d'água que ressurgiram após o renascimento das plantas.

Embora não tenha um programa de educação ambiental, o empreendimento preza pela preservação do meio ambiente e incentiva os funcionários e visitantes que preservem a natureza, zelando pelo bem comum presente na localidade.

Na RPPN Ninho do Corvo, a atividade turística é desenvolvida de forma organizada e com controle da capacidade de carga, proporcionando a durabilidade dos recursos naturais e permitindo a continuidade da restauração da vegetação. A gestão responsável e consciente se constitui como fator determinante para o sucesso da proposta de uso de uma área de preservação. Além do mais, desenvolver atividades de turismo em áreas preservadas é uma maneira de educar o visitante, propagar a importância da preservação do meio ambiente e disseminar a diversidade de espécies da fauna e da flora presentes no local.

\subsubsection{Contribuições econômicas}

Atualmente, a comunidade se beneficia com a presença dos turistas que se deslocam até o empreendimento turístico. Esse movimento gera renda adicional para a comunidade e empregos, como o de dois funcionários fixos e duas freelancers da cozinha que residem na comunidade da RPPN, na Linha Paraná.

Depois que a comunidade passou a receber turistas, o funcionário F relata que foram percebidas modificações no município, pois é um fluxo constante de pessoas que realizam suas compras, passeiam por outros atrativos e, por causa delas, há empregos para a comunidade local.

Mesmo sendo valores pequenos e esporádicos, os freelancers relatam ter uma melhoria financeira, e esses valores fazem diferença no seu dia a dia, pois são vistos como um complemento de renda e que auxilia nas despesas familiares.

Além dos empregos diretos e indiretos que são gerados para atender às necessidades do Ninho do Corvo, as duas propriedades do entorno que traba- 
Iham com atividade turística e que foram incluídas nesta pesquisa auxiliam no desenvolvimento da comunidade por meio de suas demandas, e os turistas que frequentam uma propriedade acabam conhecendo a outra também.

Não há um dado preciso sobre essa relação, mas acredita-se que muitos turistas visitam o município motivados pela presença das cachoeiras. Portanto, eles realizam um roteiro variado de um a três dias, muitas vezes definido por eles mesmos, englobando vários atrativos naturais, de forma a proporcionar uma sinergia involuntária entre os empreendimentos turísticos do município.

Por fim, há uma contribuição econômica para o município como um todo, pois a demanda atraída pela RPPN Ninho do Corvo também desfruta de equipamentos e serviços disponibilizados no centro do município, como hospedagem, refeições, consumo em bares, supermercados, farmácias etc.

O estagiário B acredita que o fato de ser uma área de preservação ajuda a chamar atenção para o município, e quem visita a RPPN acaba divulgando Prudentópolis em sua totalidade, ajudando indiretamente no desenvolvimento.

Ainda, por meio de passeios e compras em feiras de artesanatos e exposições, há uma colaboração indireta que envolve a movimentação da economia do município e a renda dos pequenos produtores de artesanatos e produtos típicos da gastronomia.

\section{CONSIDERAÇÕES FINAIS}

Esta pesquisa teve como objetivo caracterizar o empreendimento turístico Ninho do Corvo e suas ações para o desenvolvimento local. Trata-se de uma propriedade particular localizada em Prudentópolis, PR, adquirida em 2002, que teve oito de seus 25 hectares transformados em área de preservação, por meio de uma Reserva Particular do Patrimônio Natural, pertencendo ao grupo de Unidades de Conservação de Uso Sustentável.

O processo natural de recuperação das áreas degradadas por meio das queimadas, plantio de grãos e uso contínuo do solo foi lento e trouxe diversas transformações para o ambiente, tais como o ressurgimento de espécies da flora e da fauna e nascentes d'água que haviam secado. 
O empreendimento turístico RPPN Ninho do Corvo contribui, dentro de suas limitações, para o desenvolvimento ambiental, por meio da instalação de uma área de preservação, pois, além de permitir a restituição das diversas espécies da fauna e da flora da região, proporcionou o ressurgimento de nascentes d'água, melhora da qualidade do ar na propriedade, impedimento da erosão e da degradação do solo causadas pela lavoura, pecuária e prática de queimadas.

Por meio da prática das atividades de turismo, foi necessária a contratação de funcionários fixos e de freelancers que auxiliam principalmente na alta temporada, tanto no preparo de alimentos quanto na condução e no acompanhamento das atividades de aventura. Ainda, o auxílio de estagiários nos treinamentos vivenciais permite a interação com o meio ambiente estudado em sala de aula e proporciona novas oportunidades e contatos para eles.

Por outro lado, por meio da atividade turística, há a geração de emprego e de renda extra para algumas famílias, bem como a contribuição para o incremento de outras propriedades e empreendimentos que compõem a infraestrutura de atendimento ao turista, tais como hotéis e restaurantes. Portanto, pode-se dizer que há contribuição para o desenvolvimento econômico local e municipal.

Embora em pequenas proporções, entende-se que o empreendimento turístico Ninho do Corvo auxilia para o desenvolvimento econômico e social do entorno. Há a geração de renda direta para os funcionários fixos e, esporadicamente, para os freelancers. O comércio local tem a oportunidade de atender os turistas que visitam a RPPN, seja por meio de hospedagem nos hotéis e pousadas do centro, seja por meio dos outros empreendimentos turísticos vizinhos, além de haver a ligação entre atrativos, sendo que turistas que visitam o empreendimento estudado, sempre que possível, acabam visitando outras propriedades vizinhas e no município.

Constatou-se certa colaboração com o desenvolvimento social, no âmbito da amostra pesquisada, não sendo possível generalizar esses resultados. Trata-se de funcionários e colaboradores sem experiência prévia e que foram ensinados e treinados com o passar do tempo. Dessa forma, fica evidente a valorização social dada aos moradores do entorno. 
Vários funcionários relataram mudanças em suas vidas em virtude de estarem inseridos no empreendimento. Por meio de oportunidades de realização de cursos, de conhecimentos de novas realidades, pessoas e atividades, por estarem em contato com atividades sustentáveis e um local de preservação, que ensina a cuidar da natureza da forma correta, preservando os bens naturais, as pessoas envolvidas passam a adquirir novas visões e posicionamentos acerca do meio ambiente, das relações com as pessoas, e encontram oportunidades únicas.

Para aprimorar o atendimento e os serviços prestados, os funcionários realizaram cursos de capacitação: de boas práticas na manipulação de alimentos; primeiros socorros; e condutor de atividades de aventura. Por meio desses cursos e do contato com novas realidades, conhecimentos e experiências, os funcionários tiveram modificações em suas rotinas, desenvolvendo novas habilidades e sensibilização ambiental, disseminando a sustentabilidade em suas famílias e no dia a dia.

Embora não haja cursos específicos sobre educação ambiental, nota-se que há uma sensibilização por parte dos funcionários e turistas, que entendem a importância da área de preservação e de ter atitudes condizentes com o cuidado em relação ao meio ambiente. Percebem-se fragilidades que podem ser trabalhadas junto à comunidade, buscando envolver os moradores e escolas em visitas guiadas, projetando o cuidado com os recursos naturais, de forma sustentável e consciente.

Vale ressaltar que a área em questão é uma Reserva Particular do Patrimônio Natural e não há outra no município, portanto, serve de exemplo e modelo para que novas propriedades sejam transformadas, visando à preservação do meio ambiente aliada com a atividade turística.

A presença da RPPN e o consequente desenvolvimento das atividades de turismo contribuem para o incremento econômico do entorno onde está inserido, visto que geram empregos, renda, e favorecem o desenvolvimento dos empreendimentos turísticos vizinhos e do município, por meio das visitações dos turistas a outros atrativos, hotéis, restaurantes e lojas da cidade e da região.

Para melhorar a relação entre os empreendimentos turísticos do município de forma que haja uma sinergia em prol do desenvolvimento 
da atividade turística e do aumento da renda, sugere-se que sejam feitas parcerias entre os atrativos, desenvolvendo pacotes interligando segmentos e atrativos.

É necessário que sejam pensadas diversas ações para trazer benefícios aos envolvidos com o turismo, seja direta ou indiretamente. Um desses pontos pode ser desenvolvido pelo poder público, no que diz respeito a ações que visem ao embelezamento da cidade, por exemplo, incentivando os moradores a cuidar das fachadas de suas casas, do comércio, como forma de atrair o visitante. O turismo é uma corrente que envolve diversos atores e atividades, e para que tenha sucesso é preciso a união de todos, pois é aos poucos que se constrói um grande atrativo.

Espera-se que esta pesquisa sirva de subsídio para o desenvolvimento de novos estudos na área do turismo, de forma que haja melhorias tanto no planejamento como na execução das atividades turísticas do município e da região. De forma similar, almeja-se que o poder público e o empresariado local se unam para desenvolver políticas públicas e projetos, podendo utilizar os resultados deste estudo como base para desenvolver ações que visem a melhorias tanto para a comunidade local como para os empreendimentos turísticos.

Assim, promoveriam as belezas culturais, as tradições e, principalmente, os atrativos e recursos naturais existentes no município, criando possibilidades de desenvolvimento econômico, social e ambiental.

\section{REFERÊNCIAS}

BANDUCCI JR, Álvaro; BARRETO, Margarita (Org.). Turismo e identidade local: uma visão antropológica. Campinas, SP: Papirus, 2001.

BRASIL. Ministério do Turismo. Turismo de aventura: orientações básicas. 3. ed. Brasília-DF: Ministério do Turismo, 2010.

BRASIL. Lei n. 9.985, de 18 de julho 2000. Regulamenta o art. 255, § 10, incisos I, II, III e IV da Constituição Federal, institui o Sistema Nacional de Unidades de Conservação da Natureza e dá outras providências. Diário Oficial da União, BrasíliaDF, 18 de jul. 2000. 
Vanessa ALBERTON; Luis Paulo Gomes MASCARENHAS;

Ronaldo Ferreira MAGANHOTTO; Cláudio Shigueki SUZUKI

CEBALLOS-LASCURÁIN, Hector. Introdução: o ecoturismo como um fenômeno mundial. In: LINDBERG, K.; HAWKINS, D. E. Ecoturismo: uma guia para planejamento e gestão. 3. ed. São Paulo: Editora SENAC, 2001. p. 23-29.

DIAS, Reinaldo. Turismo sustentável e meio ambiente. São Paulo: Atlas, 2003.

EMBRAPA. Alternativas ao uso do fogo na agricultura e as etapas para planejamento de uma queimada controlada. Brasília-DF: Embrapa, 2015. Disponível em: https:// www.embrapa.br/busca-de-noticias/-/noticia/2471085/alternativas-ao-uso-dofogo-na-agricultura-e-as-etapas-para-planejamento-de-uma-queimada-controlada. Acesso em: 30 maio 2016.

EMBRATUR. Diretrizes para uma política nacional de ecoturismo. Brasília-DF: EMBRATUR, 1994.

FENNEL, David A. Ecoturismo: uma introdução. São Paulo: Contexto, 2002.

FREITAS, Henrique; OLIVEIRA, Mírian; SACCOL, Amarolinda Zanela.; MOSCAROLA, Jean. O método de pesquisa survey. Revista de Administração, São Paulo, v. 35, n. 3, p. 105-12, jul./set. 2000.

GIL, Antonio Carlos. Como elaborar projetos de pesquisa. 4. ed. São Paulo: Atlas, 2002.

GOMES, Mariana Elias. Reflexões acerca da relação entre turismo e cultura. Revista Espaço Acadêmico, Maringá, ano VII, n. 73, [s.p.], jun. 2007.

GONZÁLEZ REY, F. Pesquisa qualitativa em psicologia: caminhos e desafios. São Paulo: Pioneira Thomson Learning, 2002.

INSTITUTO AMBIENTAL DO PARANÁ. Dados sobre RPPN no Estado do Paraná. Curitiba: IAP, 2017. Disponível em: http://www.iap.pr.gov.br/modules/conteudo/ conteudo.php?conteudo=1232. Acesso em: 20 jun. 2018.

INSTITUTO AMBIENTAL DO PARANÁ. Roteiro para planejamento de RPPNs no Estado do Paraná. Curitiba: IAP/DIBAP/DBio; DUC/Projeto Paraná Biodiversidade, 2009.

INSTITUTO BRASILEIRO DE GEOGRAFIA E ESTATÍSTICA. IBGE cidades, 2010. Disponível em: http://cidades.ibge.gov.br/xtras/perfil.php?codmun=412060. Acesso em: 24 fev. 2015. 
LOPES, Gerson Luiz. Floresta ombrófila mista. Compêndio Online Gerson Luiz Lopes, Guarapuava, Laboratório de Manejo Florestal - Unicentro, 2012. Disponível em: http://sites.unicentro.br/wp/manejoflorestal/florersta-ombrofila-mista/. Acesso em: 20 fev. 2015.

MINAYO, Maria Cecilia (Org.). Pesquisa social: teoria, método e criatividade. 29. ed. Petrópolis, RJ: Vozes, 2010.

PARANÁ (Estado). Secretaria de Estado do Turismo. Diretrizes para o turismo em áreas naturais no Paraná. Curitiba: SETU, 2000. Disponível em: http://www. obsturpr.ufpr.br/artigos/diretrizesturismoareasnaturais.pdf. Acesso em: 26 ago. 2015.

PIRES, Paulo dos Santos. Dimensões do Ecoturismo. São Paulo: SENAC, 2002.

PRUDENTÓPOLIS (Cidade). Inventário da oferta turística de Prudentópolis. Prudentópolis: Secretaria Municipal de Turismo, 2015.

REJOWSKI, Mirian; COSTA, Benny Kramer (Org.). Turismo contemporâneo: desenvolvimento, estratégia e gestão. São Paulo: Atlas, 2003.

RPPN NINHO DO CORVO. Plano de manejo da RPPN Ninho do Corvo. Guarapuava: [s.I.], 2009.

RUSCHMANN, Doris van de Meene. Turismo e planejamento sustentável: a proteção do meio ambiente. Campinas: Papirus, 1997.

SACHS, Ignacy. Desenvolvimento: includente, sustentável, sustentado. Rio de Janeiro: Garamond, 2004.

SERVIÇO GEOLÓGICO DO PARANÁ [MINEROPAR]. Atlas geomorfológico do Paraná. Curitiba: UFPR, 2006.

SCÓTOLO, Denise; PANOSSO NETO, Alexandre. Contribuições do turismo para o desenvolvimento local. Revista de Cultura e Turismo, Ilhéus, ano 9, n. 1, p. 36-59, fev. 2015.

SWARBROOKE, Jhon. Turismo sustentável: meio ambiente e economia. Aleph: São Paulo, 2000. V. 2.

UNESCO. La Carta de Belgrado: un marco general para la educación ambiental. Iugoslávia: Unesco, 1975. 
Vanessa ALBERTON; Luis Paulo Gomes MASCARENHAS;

Ronaldo Ferreira MAGANHOTTO; Cláudio Shigueki SUZUKI

VIANA, Fernanda Cauper; NASCIMENTO, Marcos Antonio Leite. O turismo de natureza como atrativo turístico do município de Portalegre, Rio Grande do Norte. Pesquisas em Turismo e Paisagens Cársticas, Campinas, v. 2, n. 1, 2009. [SeTur/SBE]. 